\title{
Transforming Masculinist Political Cultures? Doing Politics in New Political Institutions*
}

\author{
by Stephanie Jones, Nickie Charles and Charlotte Aull Davies \\ Swansea University, University of Warwick, Swansea University
}

Sociological Research Online, Volume 14, Issue 2,

$<$ http://unw. socresonline.org.uk/14/2/1.htm/>

doi:10.5153/sro. 1863

Received: 10 Sep 2008 Accepted: 27 Jan 2009 Published: 31 May 2009

\begin{abstract}
In the devolved legislative assemblies of Scotland and Wales the proportion of women representatives is approaching parity. This is in marked contrast to Westminster where one in five MPs are women. In this paper we explore the extent to which the masculinist political cultures characterising established political institutions are being reproduced in the National Assembly for Wales or whether its different gendering, both in the numbers of women representatives and in terms of its institutional framework, is associated with a more feminised political and organisational culture. Drawing on interviews with half the Assembly Members, women and men, we show that the political style of the Assembly differs from that of Westminster and that Assembly Members perceive it as being more consensual and as embodying a less aggressive and macho way of doing politics. AMs relate this difference to the gender parity amongst Assembly Members, to the institutional arrangements which have an 'absolute duty' to promote equality embedded in them, and to the desire to develop a different way of doing politics. We suggest that the ability to do politics in a more feminised and consensual way relates not only to the presence of a significant proportion of women representatives, but also to the nature of the institution and the way in which differently gendered processes and practices are embedded within it. Differently gendered political institutions can develop a more feminised political culture which provides an alternative to the masculinist political culture characterising the political domain.
\end{abstract}

\section{Keywords: Gender, Political Culture, New Political Institutions, Consensus Politics, Political Style, National Assembly for Wales}

\section{Introduction}

$1.1 \mathrm{It}$ is now ten years since the advent of devolved government in Wales and Scotland and the election of unprecedented numbers of women to both the National Assembly for Wales and the Scottish Parliament. Moreover it is twelve years since the proportion of women MPs at Westminster doubled as a result of the 1997 general election and the landslide victory of New Labour. Despite this, it is still only one in five MPs at Westminster who are women. However, in the devolved legislatures the situation is different. In the National Assembly for Wales, for instance, one in two Assembly Members (AMs) are women which makes it the world leader in terms of attaining a gender balance in legislative assemblies (Watt, 2003). This increase in the number of women political representatives was met, in Wales and Scotland, by considerable optimism on the part of women's organisations who anticipated that it would mean changes in the way politics was done and in the sorts of policies that were developed (Betts et al, 2001). It has also given rise to a considerable amount of research into whether or not women make a difference and, if so, in what ways and under what conditions (Chaney et al, 2007; Mackay, 2004; Childs, 2004b; Lovenduski, 2005; Childs and Krook, 2006; Mackay, 2008; Studlar \& McAllister 2002).

1.2 In the discussion that follows we suggest that the question of whether women make a difference has, to some extent, already been answered by those concerned with the relation between descriptive and substantive representation (Mackay, 2004; Childs and Krook, 2006). Women have been shown to have different political concerns - as in the recent vote on abortion legislation in the UK, for instance, where they were more pro-choice than their male counterparts (Today in Parliament - 23/5/08) - they have different policy priorities (Chaney 2003; Chaney et al. 2007; Ross, 2002) and they tend to see themselves as representing women (Tremblay, 2003; Childs, 2004b). Thus women MPs at Westminster 'identify the articulation of women's concerns as part of their representative function' (Childs, 2001:181). These 
differences are, however, mediated by political party, by the constraints imposed by the institutional framework within which women are working, by generation and by political culture (Stokes, 2005). There is therefore considerable evidence that the presence of women within legislative assemblies makes a difference. Whether or not this amounts to a transformation in masculinist political cultures is, however, debatable. In what follows we explore this question by focussing on a new political institution and investigating its gendering, in terms both of the way it is structured and its political culture.

\section{The gendering of political organisations}

2.1 Political parties and legislative assemblies are, along with other bureaucratic organisations, gendered, with state hierarchies being structured in such a way that men predominate at higher levels where they can wield positional power (Acker, 1990; Witz and Savage, 1992; Halford and Leonard, 2001). They are also associated with masculine cultures and the institutionalisation of a particular form of masculinity which is linked to race and class (Kenny, 2007). It has been argued that different branches of the state are more or less masculinised, something which is apparent in both the personnel and culture of the state apparatus (Franzway et al, 1989). In Joni Lovenduski's words, 'British political institutions are characterised by a culture of traditional masculinity that is a major obstacle to women' (Lovenduski, 2005:46). This predominance of men in positions of power and a culture which is hostile to women are reproduced not only through formal mechanisms, such as selection procedures, but also through informal means such as sexual harassment, the sexualisation of women and male forms of socialisation, all of which serve to make women feel out of place (Wajcman, 1998; Charles and Davies, 2000; Puwar, 2004). Moreover women's incursions into such organisations are often met by resistance (Cockburn, 1991) although there is some evidence that the changing technological basis of work and shifting organisational structures are associated with differently gendered organisations, at least in the public sector (Connell, 2006).

2.2 Some attention has been paid to the ways in which the cultures of political parties are masculinist and the formal and informal means by which women are discriminated against in selection procedures (Lovenduski, 2005; Liddle and Michielsens, 2000, 2007). Although the procedures are different, the findings parallel those from studies of recruitment and selection procedures in other types of organisation which, as well as revealing formal discrimination, expose the informal means by which women and other minority groups are disadvantaged. These informal means are part of the culture of organisations and reproduce their gendered nature, ensuring that men continue to dominate positions of power and authority within them. They are also underpinned by the gendering of power itself and its cultural association with men and masculinity. Indeed Puwar argues that political power is embodied and that 'the white, male body is taken to be the somatic norm within positions of leadership and the imagination of authority' (Puwar, 2004:67). If women aspire to powerful positions they are subject to questions about not only their femininity but also their sexuality (Cockburn, 1991). Moreover, women, unless they come from a certain class background, do not have the right 'habitus' or sense of entitlement either to put themselves forward for selection as candidates or to be selected; much in the way that women are reluctant to put themselves forward for promotion and may not be seen as capable of doing the job even if they do (Charles and Davies, 2000).

2.3 Legislative assemblies are similarly marked by a masculinist culture and have been characterised as 'institutionally sexist' (Lovenduski, 2005). This institutional sexism is clear from the experiences of women political representatives. Thus women in the UK House of Commons are faced by a level of sexual harassment that has been outlawed for decades in other places of work (Lovenduski, 2005; Sones et al, 2005) and similar practices have been noted elsewhere (Ross, 2002). Moreover, 'the declamatory, adversarial style of Westminster debate... favours rhetoric, speechifying, posturing and arcane practice in the House of Commons rather then cooperation, consensus-seeking and real discussion of alternatives. Political practices involving demagoguery, ruthlessness and aggression require qualities that are culturally accepted in men but not women' (Lovenduski, 2005:54). Women who have had to contend with this culture have adapted by adopting a masculine style themselves (Childs, 2004a) and, after the 1997 general election, many of Labour's new women MPs 'suggested that the dominant style of the House was not conducive to women acting in a feminised way' (Childs, 2004a: 8). However, with the advent of larger numbers of women representatives there is some evidence that adopting a masculine mode of behaviour is no longer the only means of political survival (Freedman, 2002; Childs, 2004; Chaney et al, 2007). Indeed, having more women representatives may not only affect women's political style but may also enable some men to adopt a more feminised political style (Bochel and Briggs, 2000; Childs, 2004; Grey, 2002; Ross, 2002; Freedman, 2002; Mackay et al, 2003). This suggests that, as well as being met by resistance and having to adopt a masculine way of doing politics in order to be taken seriously, when women enter these bastions of male power they may succeed in challenging at least some of the cultural practices which characterise them. Such cultural change, however, may only become possible when there are more than just one or two token women within a legislative assembly. 
encapsulated in the term critical mass and there has been a general acceptance of this idea in practice. However, it has been pointed out that critical actors are as, if not more, important than critical mass (Dahlerup, 2006; Childs and Krook, 2006; Grey, 2006; Tremblay, 2006; Grey, 2002). Thus there are examples of policies relating to feminist demands being taken forward by key women politicians, even in the absence of a critical mass of women. The case of the reduction of VAT on sanitary products is one such example (Childs and Withey, 2006) as is the Equal Pay Act which was taken forward by Barbara Castle in the context of EU directives on equal pay, a nascent women's movement and the Ford women machinists' strike (Charles, 2000). Furthermore, in answering the question of what difference women make, Drude Dahlerup suggests that there are six areas that need to be looked at; these relate not only to policy change but also to the way politics is done (Dahlerup, 2006:513; see also Ross, 2002). They include 'Changes in the social climate of political life (the political culture)' which she defines as taking a 'workplace perspective' and it is this aspect of change that we concentrate on in what follows (Dahlerup, 2006:513). We focus on a new political institution, the National Assembly for Wales (NAW) whose rituals and practices only came into being in 1999 and which attempted to distance itself from what was perceived as the 'yahboo' politics of Westminster. In order to do this we look first at the ways in which the NAW differs from Westminster and how gender and equality issues were central to the way it was set up. We then explore the views of AMs on the political style which characterises this new political institution, the extent to which they understand it in terms of gender and the working practices which the Assembly embodies. We conclude by suggesting that the culture of the NAW is not as strongly masculinist as that of Westminster and that this is due both to the gender balance which characterises it and to the fact that its establishment was seen as marking a decisive break with the way politics is done at Westminster.

\section{A new institution}

3.1 The National Assembly for Wales differs from Westminster both culturally and in terms of its institutional framework. There are a number of reasons for this, one being the set of expectations about the nature of the NAW that developed during the process of its creation, when it was explicitly argued that it would embody a Welsh 'style' that was different from the adversarial style of Westminster. During the devolution campaign the cross-party 'Yes for Wales' group advanced an ideal of inclusiveness in the proposed democratic arrangements for an elected body which was born from their experience of cooperative campaigning. After the referendum, during the period of negotiation about the working arrangements for the NAW, this ideal was developed further (Chaney, Hall and Dicks 2000). The initial motivation for introducing the principle of inclusiveness was to make a degree of proportional representation somewhat more palatable, or less recognisable, to its opponents within the Labour Party (Chaney and Fevre 2001). However, as the concept developed, it became linked to gender and other equality issues and was seen as fundamental to the expectations regarding both the political make-up and the political style of the new assembly, in particular to the idea that political parties would work cooperatively.

3.2 In addition, as in Scotland and Northern Ireland, feminist and women's organisations were centrally involved in developing the new institutional arrangements; they were influential in ensuring a more equal representation of women and that equality issues were taken seriously by the new body (Brown et al, 2002; Chaney et al, 2007). One outcome of this was the issue of gender equality being made integral to the NAW during the process of providing it with a legal framework within the British state. Specifically, clause 120 of the 1998 Government of Wales Act obliged the National Assembly to consider equality of opportunity throughout all its business ${ }^{[1]}$. Several of the women who campaigned for this duty to be enshrined in the new institution are now AMs and some are ministers (Mackay, 2004).

\section{Women's descriptive representation}

4.1 The other major difference is the gender balance of political representatives within the Assembly which results from the fact that the first Assembly elections provided an opportunity to ensure that women were well represented amongst Assembly Members. This was facilitated by the fact that it was a new political institution, that proportional representation had been introduced which tends to be associated with higher proportions of women being elected (Tremblay, 2006), and that the two main political parties in Wales, Labour and Plaid Cymru, took measures to ensure a more even gender balance of representatives. ${ }^{[2]}$ As a result there has always been a strong representation of women in the National Assembly for Wales. During the first Assembly, elected in $1999,40 \%$ of the seats were held by women, this rose to $50 \%$ after the second election in 2003 and fell slightly to $47 \%$ after the third election in 2007.

\section{The study}

5.1 Our research explores the gendering of political processes in Wales subsequent upon devolution and focuses on the second session of the Assembly from May 2003 to May 2007. This was prior to the introduction of increased powers by the new Government of Wales Act 2006 when the NAW's powers were 
limited to the enactment of secondary legislation primarily in the areas of agriculture; culture; education and training; the environment; health; sport; economic development; local government and housing; social services; transport and the Welsh language. We interviewed 31 AMs from all four political parties, as well as two independents, aiming for a representative mix both of the four political parties and of men and women. This can be seen in Table 1. Interviews were conducted either in Welsh or English, according to the interviewee's preference. ${ }^{[3]}$

Table 1: AMs by gender and party

$\begin{array}{lllll} & \begin{array}{l}\text { In Assembly } \\ \text { Women }\end{array} & \text { Men } & \begin{array}{l}\text { Interviewed } \\ \text { Women }\end{array} & \text { Men } \\ \text { Labour } & 19 & 10 & 15 & 16 \\ \text { Plaid Cymru } & 6 & 6 & 4 & 5 \\ \text { Conservative } & 2 & 9 & 0 & 3 \\ \text { Lib Dem } & 3 & 3 & 2 & 1 \\ \text { Independent } & 1 & 1 & 1 & 1 \\ \text { Total } & 31 & 29 & 15 & 16\end{array}$

5.2 At the time of interviewing the percentage of women AMs was 50 per cent or, for a time, slightly higher. Thus we were looking at a body in which women's representation was well above the $30 \%$ that is often taken as indicating the tipping point at which women can begin to have an effect on political culture (see Childs and Krook, 2006 for a critique of this idea). We were therefore considering an elected representative body in which gender equality, in terms of numbers at least, had been achieved. In order to explore the question of political culture, we asked AMs to describe the working environment in the NAW and also to talk about whether they would characterise its political style as consensual or adversarial. We then asked whether they thought that the gender balance of the NAW contributed to the way politics was done and the working environment.

\section{A new political culture}

6.1 In discussing the political style of the Assembly, many AMs mentioned its difference from Westminster and they related this both to the gender balance and to the fact that it was a new Welsh institution.

Certainly compared with the House of Commons, that is very different, very different. The House of Commons is incredibly male dominated, often openly misogynistic by some of the attitudes you'll get, some of the male MPs, and I think the air of the Assembly is very different but to what extent it's down to the greater gender balance or having gender balance or just because the way the Assembly works, it is a new institution, very explicitly being designed to be inclusive, it is very difficult to decide... (Male Labour)

6.2 Another male AM spoke about Westminster as a 'male club', relating this to the availability of alcohol and places in which to drink it. The NAW is different.

I think that one of the interesting things is that there is only one - well in the old building as it was, before the chamber was opened - there was only one ... one place in the Assembly that sold alcohol, for example, and that was comparatively limited, ... and there is one other place now in the new Senedd, but only two places in the entire building that sell alcohol. When one thinks about Westminster, which is more like some kind of club for men, and that element is very obvious in it ... women see the Assembly as a place to do their work, to carry out work, and then leave. And I think ... that creates an ethos, creates an atmosphere, which is directed much more towards carrying out work, and for the institution to be an institution that carries out work. (Male Plaid Cymru, translated from Welsh)

6.3 The size of the NAW also has an effect on the way politics is done and a more personal style of politics 
has developed. There are only $60 \mathrm{AMs}$ and this means that ministers are accessible and it is possible for AMs to go directly to them with issues that affect their constituencies. Thus, a male Plaid Cymru AM said, 'you can ask for an emergency meeting with the minister, or at least bring the matter to the attention of the minister straight away', noting that in Westminister 'you would have to organise a formal meeting'. And furthermore a body with 60 elected representatives is one in which members will meet one another regularly, both in the debating chamber and outside, often in quite informal social contexts. It is also noteworthy that Wales is itself a comparatively small unit with quite dense social networks, so there are likely to be ties both inside and outside the NAW (Charles, 1995). One of the male AMs told us,

I mean you can't compare us to Parliament in some ways because we are only 60 members and with that number of people, I have had this discussion this morning with the Presiding Officer, you can't, you are in each other's pockets all the time. I mean, literally you can't avoid people and, you know. Whereas in Parliament, if you, if you want to create an image or faction or whatever else, you can go into a corner with a huddle of a hundred people and do your thing, but you can't do that here. (Male Liberal Democrat)

6.4 There was also some indication that party affiliation made a difference to political style. In particular one woman Plaid Cymru AM felt that the Conservatives, the majority of whom were men, had more of a Westminster style than the other parties: 'I mean they are, it is noticeable that they shout more than everybody else does, and very much in the House of Commons style.' Numerically and culturally then the Conservative AMs would seem to have a more masculine style of politics than AMs from the other political parties (see also Chaney et al, 2007:201-2).

\section{Consensual politics}

7.1 Given the emphasis of the Assembly, particularly in its first session, on consensual politics, and the conscious effort not to adopt the adversarial style which was seen as characterising Westminster, and also in view of the fact that a more consensual political style is often understood as a more feminine way of doing politics, we asked AMs whether they would characterise the political style of the Assembly as consensual or adversarial. Of the $31 \mathrm{AMs}$ interviewed, just over a third (5 women and 6 men) described the politics of the NAW as broadly consensual while just under two thirds (10 women and 10 men) felt it was more adversarial. These views had no discernible link with political party with the exception of the Liberal Democrats, all three of whom ( 2 women and 1 man) described it as consensual.

7.2 There are, however, different meanings given to the terms adversarial and consensual with most of the AMs qualifying their assessments of the nature of the overall political style in various ways. Some saw it as having changed over time, some questioned whether or not consensual politics was in fact desirable, and some suggested that political style varied depending on context and on the policy area under discussion. We look at these different understandings of consensual and adversarial politics in turn.

7.3 There was a view that the political style of the Assembly was evolving with some AMs describing a gradual process of transformation from the early days of the NAW when people were finding their feet and only a very few had any previous experience as an elected politician.

I believe in the beginning there were ... out of 60 only 7 were a ...//... Member of Parliament, so there were 53 completely new politicians in 1999, and I believe... that affected people who were all trying to find their way at the same time, and I believe things were more consensual when everyone was lost, as it were. But now everyone has found their feet, basically, and there are issues, you know, quite important before us, especially the health service, waiting lists and so on; there is quite a lot of conflict there ... Basically I believe that everyone has got enough confidence, everyone has found their way around the place now, and more and more ready to be oppositional as well, I believe comes with political experience. (Male Plaid Cymru, translated from Welsh)

7.4 In this early period the NAW was seen as perhaps still embodying the vision of Ron Davies ${ }^{[4]}$ who had argued for its 'inclusivity', interpreted to mean cross-party cooperation. Thus a woman AM (Plaid Cymru) said, '...Ron Davies's vision for how the Assembly would work, and the voting system, was supposed to force us into, with nobody ever being able to get a very good majority and so forth, it was supposed to force us into working together.' This style was seen to have begun to alter even in the first session (1999-2003) as parties approached the 2003 election. In the second session Rhodri Morgan, who was First Minister in the Welsh Assembly Government (WAG), began the process of distinguishing the Welsh Assembly Government from the National Assembly, and a few AMs specifically pointed to that as the main impetus for the development of a more adversarial politics. A male Conservative AM said: 
of the Assembly, but obviously originally, the original Government of Wales Act established the Assembly as a single consensual body. That was blown out of the water when we had the formal, the announcement when Rhodri Morgan when he took over, we were going to have not an Executive any longer but an Assembly Government with Cabinet, with Ministers, separation of departments away from the Parliamentary Service; of course that has now been formalised in the Second Government of Wales Act, a formal separation between the two. So it has already become, therefore, an adversarial body in law, and that is going to grow as far as I can see...(Male Conservative)

7.5 AMs differ in their assessments of the desirability of consensual and adversarial politics. To a degree this reflects their particular understanding of what this dichotomy actually means. Several interpreted adversarial as oppositional politics and expressed concern about the lack of any clear opposition to the Welsh Assembly Government, again particularly in the early years of the NAW. A Conservative AM was asked the extent to which the Assembly engaged in consensual politics. He replied:

Too much so in my opinion, I must say, far too much. I don't think consensual politics works, I call it sitting room politics, I think it's utterly boring. I mean I just think the politics in the Chamber should really be what's termed adversarial, but I think the word adversarial is a prejudiced word, but I just do think that the discussions we should have should essentially be about things we disagree about. (Male Conservative)

7.6 A similar view could be found among women and in other parties; a Plaid Cymru woman AM told us, 'I think consensus politics is a nice idea in principle, but ... it can be unhealthy, because if you are not getting, if you are putting an idea out there and you are not getting proper scrutiny of it, then that isn't healthy and it isn't good for, well it's going against the whole reason for wanting debate.' (Female Plaid Cymru)

7.7 Certainly the Presiding Officer, Plaid Cymru AM Dafydd Elis Thomas ${ }^{[5]}$, is on record as believing the NAW is too consensual and that it will have to adopt a more clearly oppositional format in order to operate effectively as it acquires more powers under the new devolution settlement. On the other hand, he provides an important example of how the concept of adversarial politics is often qualified, seeing it as oppositional without necessarily being aggressively confrontational. This then was one interpretation of the meaning of adversarial politics, a politics which encompassed an effective opposition to the Welsh Assembly Government.

7.8 Another way of talking about consensus politics related to cross-party collaboration between women. This highlights a different interpretation of consensus as relating to policy areas where there is agreement between political parties. An illustration of this is provided by the process of establishing the Children's Commissioner for Wales, as described by the two women primarily involved, a Labour minister and a Plaid Cymru AM. The minister said:

...we came together on appointing, agreeing we should have a Children's Commissioner and agreed to have the legislation, worked together to appoint a Children's Commissioner. We actually engage opposition Assembly Members in public appointments and more, you know, nine times out of ten that results in a consensus choice. (Female Labour)

7.9 While the Plaid Cymru AM described the process from her view point:

...when we were working to develop the Children's Commissioner, [...the Minister] .. for Heath and Social Services, sent me to do all the participation work with the young people, because she knew that I knew how to do that professionally. Now you cannot imagine in Westminster, you cannot imagine a Minister sending a Shadow Cabinet Minister to do a job like that. It's unthinkable, and I think some of that is to do with gender and some of that is to do with scale and some of that is to do with the individuals involved, and because she sent somebody to do that who knew what they were doing, we actually came up with a much better model ...(Female Plaid Cymru)

7.10 Several AMs named other policy areas where there was a cooperative approach because of a general agreement about policy direction.

There are issues where there is cooperation and there is, there is an effort to work together. One thinks about issues ... basic issues in terms of equal opportunity, social inclusion, sustainable development, there are efforts in that area; the Welsh language, there is a certain amount of effort there. (Male Plaid Cymru, translated from Welsh) 
So in relation to particular issues there could be extensive cross-party cooperation which was viewed as an important dimension of consensual politics.

7.11 Whether political style was adversarial or consensual also depended on context with many AMs feeling that there was a difference between plenary sessions in the debating chamber and committee work.

It still continues to be quite consensual in the committees, ridiculously combative in plenary and funnily enough I had thought in the new chamber, in the new round, sort of organic, womb-like chamber things might be a little friendlier. They are not at all, but then we are really in election mode, it's only 14 months 'til the next election...(Female Labour)

\subsection{Another Labour woman said:}

We would like to think, or some of us would like to think, we are consensual but it doesn't always work. I mean, it depends where you are, I mean I would say the committees tend to be much more consensual, but the plenary debates are much more oppositional, and of course running up to the election now you will get more of that. (Female Labour)

7.13 The distinction between adversarial and consensual politics was therefore understood in various ways. Adversarial politics was seen as necessary for a healthy opposition, and something which was desirable in the Chamber to produce less 'boring' and more interesting debates. However, in committee work there was evidence of considerable consensus and cross-party collaboration, particularly in relation to specific policy issues.

\section{The influence of gender}

8.1 Discussions about adversarial and consensual politics also had a gender dimension with these different ways of working being associated with different ways of performing masculinities and femininities. For some an adversarial style was associated with macho and aggressive forms of masculinity. One of the women Ministers, whom we interviewed in the run up to the 2007 election, distinguished between oppositional and aggressively adversarial politics.

Parties are at each other's throats in the advance of the election. So we have returned to sort of naked tribalism, and naked tribalism, you know, it's, gender, gender politics, are a casualty to some extent of that approach of politics; it's very, very macho, it's all shouting. I mean the Presiding Officer is regularly having to say, particularly to [the leaders of the Liberal Democrats and the Conservatives], "you don't need to shout to make your point". (Female Labour)

8.2 In these comments she explicitly links an adversarial politics with a certain way of performing masculinity. Conversely, cooperative and consensual working was associated with femininity and there was a perception that it was more likely to be women who adopted this mode of behaviour. A woman Plaid Cymru AM described the cooperative work at committee level on the part of two Labour women ministers, observing that, 'none of the men do it, I know that, maybe not all of the women do it but none of the men do it.' Here it is acknowledged that while there may be a cultural association of more consensual ways of working with femininity, not all women adopt this mode of behaviour. Alongside this, however, went the observation that women AMs are more likely than their male peers to behave in this way.

8.3 Despite the recognition that some women AMs adopted masculine modes of behaviour, there was a widespread view that the gender balance of the NAW affected its political culture and debating style. Thus a male AM commented on the conduct of the Labour group's meetings:

Oh I think it makes, it makes a difference to the culture in which group meetings are conducted as, as l've said we have fierce disagreement in group meetings but, but it is not, it is conducted with the complete absence of chest thumping and table thumping. (Male Labour)

8.4 This suggests that neither the women nor the men in Labour group meetings adopted an aggressively macho form of masculinity. One of his female colleagues agreed about the working environment in the NAW but was reluctant to generalise about women's or men's political style.

I don't like making generalisations because I know women who are just as aggressive as men, and I know men who can be as calm and sensible as many women I know, but I think on the whole the women that I know have got a different way of working and think things through, and aren't sort of overly aggressive. (Female Labour) 
8.5 Although she acknowledges that gendered behaviour cannot be read off from sexed bodies, she also expresses the view that women and men work differently. A man from Plaid Cymru made a similar point, arguing that the presence of women had an effect on how men behaved but also emphasising that some of the women could exhibit a very assertive, even adversarial style. In his view, men were more likely to indulge in 'verbal conflict and macho behaviour' whereas, with more women present 'there is more hope of having sensible discussions'. He went on,

[T]here's not a lot ... of aggressive behaviour happening in the Assembly. Although I must say there are some, a few women who can be ... very feisty in their arguments! (Male Plaid Cymru, translated from Welsh)

8.6 The variation in the performance of gender was commented on by a woman AM from Plaid Cymru who described one of Labour's women ministers as being 'very confrontational, very manly in her approach'. She contrasted her style with that of some of the other Labour women ministers who were regarded as strong and vocal advocates of their positions but who nevertheless 'treat everybody even-handedly and will say "that's a good idea" and so on.' Thus women's political styles differed and some adopted more masculine ways of behaving than others. Despite this recognition of variability in gendered behaviour, there was also a perception that women were more likely than men to adopt consensual and cooperative forms of femininity and that men were more likely than women to adopt aggressive forms of masculinity. This view was often asserted as fact. A woman AM told us that the gender balance had,

made a tremendous difference yes, because women do things in different way, do debate in a more consensual style not, I mean many of us have learnt to be less consensual, for publicity reasons, 'cause the media aren't interested in consensus, but I mean our natural way of working is, probably more practical and more low key. (Female Liberal Democrat)

8.7 Her comments are interesting, not only because they show the cultural assumptions about femininity but also because she refers to external pressures which push politicians towards less consensual ways of behaving. In this case she mentions the media's lack of interest in consensual debates which ties in with an earlier comment on the need for an adversarial style in order to make political debate interesting. This points to the difficulties in developing a more consensual political style in light of the wider political culture and expectations held by the media about what makes interesting (and newsworthy) political debate.

8.8 It was also thought that gender parity had an impact on the type of policy issues that were debated.

It has also changed the topics of debate, you know, I would say there has been much emphasis on, family issues, and probably on, health and community issues, as a result of there being so many women... but I think that the interesting thing is, when you have got now 31 women, you are in a situation where, women pop up everywhere, and you know the Economic Development Committee, which was very male dominated in the first Assembly, became majority female, at the beginning of the second Assembly, and so really the influence is spread over every aspect, and really the only thing that remains untouched by women, is when the four leaders meet, because they are still all men. ${ }^{[6]}$ (Female Liberal Democrat)

8.9 Others also thought that women had made a difference to the policy areas discussed but not so much to the way politics was done. A Plaid Cymru AM said:

I think that more time has been given to the sort of non-traditional areas, and so you know domestic violence is on the agenda, equal pay is on the agenda and all those kinds of really important issues that probably wouldn't be there if there wasn't such a high number of women, so in terms of the issues I think it might have made a difference and in terms of the way politics is conducted I am not convinced. (Female Plaid Cymru)

8.10 And as we have seen, new institutional practices and a different political environment were also seen as contributing to the less masculinised way of doing politics which distinguishes the NAW from Westminster. As well as the gender balance and the conscious attempts of the Assembly to create a more consensual political style, there are also indications in our data that some younger men do politics in a more feminised way than older men just as some women adopt a masculinised political style. And, as we have seen, there are party differences in style with the Conservatives being more adversarial, something that is reflected in their comments about the difference between adversarial and consensual politics which imply that consensual politics is ineffectual. This suggests that there is more of a fluidity in gendered behaviours than is generally assumed and alerts us to the possibility of a 'de-gendering' of politics (Squires, 1999). 
9.1 We now turn our attention to an area of policy which is related to the working environment at the Assembly - family-friendly policy. It has been suggested that the introduction of family-friendly measures in the new political institutions has great symbolic significance, it is a sign of a culture shift and a recognition that political representatives may have family responsibilities. This is in marked contrast to the assumptions underpinning long-established legislatures such as Westminster (Ross, 2002; Lovenduski, 2005).

9.2 When the Assembly was established, 'family friendly' working hours were formalised in the Standing Orders of the NAW, which is another major institutional difference from the Westminster model. This was a result of the significant input of feminists and women's organisations into the process of establishing the NAW (Rees 1999). During the first and second sessions, the National Assembly sat only during school term time, plenary sessions were supposed to finish by $5.30 \mathrm{pm}$, and a vote had to be taken to carry on the plenary sessions after this time. Plenaries were held on Tuesday and Wednesday afternoons, with committee meetings on Wednesday and Thursday mornings ${ }^{[7]}$. There was no crèche, however, something that many of the AMs commented upon. Even though the Assembly's family-friendly hours are of symbolic importance they are not, in most AMs' views, of great practical importance, particularly for those who do not live in and around Cardiff where the Assembly is situated. A woman Labour AM talked of her own circumstances.

It's referred to as family friendly hours or environment. It is family friendly if you live in Cardiff and it's a myth more than anything. I don't see how it can be, the hours are geared up for that but that doesn't make them family friendly. To me it would make it family friendly because of my personal circumstances if we worked it in a different way. It's only family friendly if you live in Cardiff basically and I think it was drawn up with the view to collecting children from school, which I have no grumble about, that part of it, but what about people like myself with an elderly mother... what do I do if my mother needs care and needs me to come back, so it's, it's a nonsense. (Female Labour)

9.3 The issue of long-distance commuting to Cardiff and the time AMs from north and west Wales had to be away from their families was mentioned frequently. Although Wales is a small country, the geography and poor public transport links mean that travelling across country is time consuming - with a journey from north to south Wales taking about five or six hours. There was a view that the hours were helpful for AMs who had small children and lived in or near Cardiff, but for others, they were family unfriendly as it meant that AMs were away from their families for longer than they would be if Assembly business were concentrated into longer sittings on fewer days.

9.4 Proposals to change the Assembly's working hours are a constant source of disagreement and an indication of continuing attempts to 'Westminsterise' politics at the Assembly (Chaney et al, 2007:203). Some of the AMs believed that there would be an increase in working hours resulting from the new settlement, giving the National Assembly more powers from May 2007, a point that has been consistently and publicly emphasised by the Presiding Officer (Blake 2006: 6; Williamson 2008: 15). One woman minister talked about this, '...one of the propositions in terms of the new arrangements is that the hours will have to change to accommodate greater work loads, and the implication of that is that, in a sense, one of the casualties could be family friendly...... it's not just about us it's about all those civil servants out there who have to accommodate their lives around what the politicians do as well.' (Female Labour). Such proposals had come up during the first Assembly between 1999 and 2003, and the reaction by some of the AMs demonstrates the symbolic significance of the family-friendly policies of the Assembly, particularly for women AMs. It also underlines the fact that the Assembly's family-friendly hours exist not only or even mainly for the benefit of AMs but for those who work for the Assembly. The following account from a woman Plaid Cymru AM shows that she and women from other parties were prepared to unite around this 'women's' issue even when it meant going against their group's wishes.

[T]here was a move back in the middle of the first Assembly to extend the Assembly's working hours until 7 o'clock. And it was one of those issues that was kind of discussed in all the political groups, but it was the men from Westminster who were taking the lead on making the decisions, and we ended up with this proposed change to standing orders, and in the end I looked at it and I thought 'we can't do this'. Because if we are sitting until 7 o'clock, our staff are going to be here until 9, you know, the people who are doing the record of proceedings and things like that, the organisations that come and lobby us between 5.30 and 7 are going to have to be here until 9.30 or they are not going to come at all. And so, against my group's will, I said 'I am not going to stand for this and I am going to speak against it and vote against it'. And I stood up to do that and then suddenly across the Chamber, including women from within my own group, you had a, it was like 'No, I'm Spartacus'. You had women from all over the place and we kind of accepted that this was logical and this was moving us towards being a proper parliament and then suddenly we thought 'no, it's not'.....And before 
we knew where we were, what had been a cross-party agreement that kind of slipped through under the radar, fell apart in the face of the concerted group of women. And what I think is important is a concerted group of feminist women saying no, and it was defeated and the men in grey suits have never tried to bring it back again.... This is not about me and my working patterns, because I don't stop work until 9 o'clock at night. This is about the working patterns of the women who make the tea. I am not having it. (Female Plaid Cymru)

9.5 Thus, although most AMs acknowledged that, for them, the family-friendly working hours were more symbolic than real, when (male) party leaders and business managers threatened to undermine the commitment to family-friendly working, a rebellion by women AMs ensured that the policy remained intact. Despite the limitations on the practical dimension of family-friendly working for AMs, its maintenance was seen as important because it is part of the way in which the Assembly, as a place of work, recognises the family and childcare responsibilities of its employees. It is therefore an important aspect of the Assembly's duty to promote equality of opportunity. And even though the practical effects may not be significant for AMs, it is nevertheless a cultural recognition that they may have family and childcare responsibilities and indicates a distancing from more masculinist political cultures which assume that political representatives are free from such responsibilities.

\section{Conclusions}

'Viewed in the abstract, feminizing politics is like many other political processes. If feminization is a cause of change, it is also a result of it' (Lovenduski, 2005:180)

10.1 Our preliminary findings suggest that the National Assembly for Wales is characterised by a different political style and political culture from that of Westminster and that it is, to a certain extent, feminised. It is also a style which was consciously developed in opposition to the adversarial political style of Westminster as a means of establishing a distinctly Welsh way of doing politics. The idea of adversarial politics, however, as well as being associated with Westminster, was also understood as necessary in order to develop an effective opposition to the WAG. In this sense an adversarial politics was seen as healthy, although most AMs distanced themselves from the aggressive, macho posturing which is often associated with the notion of adversarial politics. Notwithstanding these different meanings of consensual and adversarial politics in the Welsh context, most AMs felt that the presence of a high proportion of women AMs had an effect both on the policy agenda and on the style of interactions between politicians, both cross-party and within-party. There was a view that women tended to do politics differently from men, a difference that was sometimes described as more consensual than adversarial. But alongside this there was a recognition that there was no essential link between gender and political style; interviewees pointed to women who adopted masculine modes of behaviour and men who adopted more feminine ways of working. This suggests that the political culture of the NAW is more feminised than that of Westminster and that, as a consequence, there is less pressure on AMs, women and men, to adopt an aggressive and macho form of masculinity.

10.2 The research was carried out during a period when women made up $50 \%$ or $52 \%$ of the elected representatives so there was self-evidently feminisation in terms of women's descriptive representation. It would, however, be unwise to attribute the more feminised style of the NAW solely to gender parity. It is clearly not numbers alone that have created a differently gendered political institution. AMs were almost unanimous in recognising that the institutional framework of the NAW had also contributed to a less confrontational style of politics. They often compared the NAW with Westminster, which was characterised as the locus for a much more masculinised style of politics. The differences in the NAW appear to have several causes, including the history of its establishment, its size, the relative lack of political experience among representatives in the first Assembly and the comparatively limited powers of the NAW. In particular feminists and other equality activists were key to the setting up of the Assembly; their goal was a legislature characterised by gender parity and its institutional arrangements reflect this (Chaney et al, 2007). They were also crucial in developing measures introduced by the Labour party and Plaid Cymru to ensure that women candidates had a fair chance of being selected and elected in the first Assembly elections. In addition many so-called women's issues, such as domestic abuse, childcare and equality issues where women have been particularly active, happen to fall within the comparatively few areas to which power to develop secondary legislation was devolved.

10.3 These findings therefore contribute to the debate about the idea of critical mass and illustrate that even in circumstances where there is gender parity, the ability to do politics differently relates not only to the presence of a significant proportion of women representatives, but also to the nature of the institution and the way in which differently gendered processes and practices are embedded within it. They also suggest that it is possible to establish political institutions that are differently gendered thereby challenging the masculinist political culture that characterises the political domain. A new institution, unlike an established one, does not have the weight of tradition and established gendered practices to contend with and is able to 
institutionalise differently gendered practices which facilitate women's representation, both descriptive and substantive, and create a more feminised and woman-friendly political organisation (see also Mackay et al, 2003). Such institutions, however, exist in the context of a wider political culture which remains highly masculinised and are under continual pressure to change the way they do politics. It remains to be seen how effective those women AMs who banded together to resist the undermining of family-friendly hours will be in resisting such pressures.

\section{Notes}

* This research was funded by the ESRC (RES 00023 1185).

${ }^{1}$ Clause 77 in the 2006 Government of Wales Act.

2 The Labour Party adopted a policy of twinning constituencies and putting up a woman candidate in one and a man in the other. Plaid Cymru put women at the top of their regional lists. These policies were not adopted without opposition within the parties and, despite their success in increasing the number of women who are elected, there are 'ongoing tensions in the application of these equalities strategies' within the parties (Edwards and McAllister, 2002). Twinning was a one-off measure and Plaid Cymru has recently modified their policy; now a man or woman can head the regional list but the second candidate on the list must be of the opposite sex.

${ }^{3}$ Five interviews were conducted in Welsh, all with male Plaid Cymru AMs.

${ }^{4}$ Ron Davies was one of the main architects of devolution in Wales and was expected to become First Minister. He was Shadow Welsh Secretary from 1992 to 1997 and was appointed Welsh Secretary in Tony Blair's first government. He resigned this position in 1998 but was an AM during the first Assembly (19992003). He was an advocate of consensual politics and wanted the new institution to build on the cross-party relationships that had evolved during the 'Yes for Wales' campaign. For example, in his 1999 Gregynog Lecture, 'Devolution: a process not an event', he said that a 'more collaborative approach doesn't weaken the political process, it strengthens it. The new National Assembly will be the stronger for it; politics will be more mature and the electors will have a more informed choice when the rhetoric and posturing is swept away.'

5 The Presiding Officer, who is elected by all AMs, serves the National Assembly impartially. It is the Presiding Officer's role to chair the Plenary and ensure that order is maintained and that AMs' rights are protected. The Presiding Officer also has to ensure that Assembly business is conducted on the basis of equality and impartiality, is responsible for Standing Orders and is the final authority on their interpretation. Dafydd Elis Thomas, who has been elected Presiding Officer in all three terms of the NAW, is widely considered to have acted effectively to enhance its public standing and legitimacy.

6 This has recently changed with the new leader of the Liberal Democrats being a woman.

${ }^{7}$ In the third session committees also meet on Thursday afternoons.

\section{References}

ACKER, J (1990) 'Hierarchies, jobs, bodies: a theory of gendered organisations' in Gender and Society , 4 (2): $139-158$

BETTS, S, Borland, J and Chaney, P (2001) 'Inclusive government for excluded groups: women and disabled people' in P.Chaney, T. Hall and A. Pithouse (eds) New governance - new democracy? University of Wales Press: Cardiff

BLAKE, B. (2006) 'The public are not getting value for money...we can do a lot better' Western Mail, 22 May

BOCHEL, C. \& Briggs, J. (2000) 'Do women make a difference?', Politics 20(2): 63-68.

BROWN A, Donaghy T B, Mackay, F and Meehan, E (2002) 'Women and constitutional change in Scotland and Northern Ireland' in Parliamentary Affairs, 55: 71-84

CHANEY, Paul (2003) 'Increased rights and representation: women and the post-devolution equality agenda in Wales' in A. Dobrowolsky \& V. Hart (eds) Women Making Constitutions: New Politics and Comparative 
CHANEY, P. \& Fevre, R. (2001) 'Ron Davies and the Cult of 'Inclusiveness': Devolution and Participation in Wales', Contemporary Wales, Vol. 14.

CHANEY, P., Hall, T. \& Dicks, B. (2000) 'Inclusive governance? The case of "minority" and voluntary sector groups and the National Assembly for Wales', Contemporary Wales, Vol. 13.

CHANEY, Paul, Mackay, Fiona, \& McAllister, Laura (2007) Women, Politics and Constitutional Change: The First Years of the National Assembly for Wales, Cardiff: University of Wales Press

CHARLES, N (2000) Feminism, the state and social policy, Palgrave: Basingstoke

CHARLES, N (1995) 'Feminist politics, domestic violence and the state' in Sociological Review, 43 (4): $617-40$

CHARLES N and Davies C, (2000) 'Cultural stereotypes and the gendering of senior management' in The Sociological Review, 48 (4):544-67

CHILDS, Sarah (2001) 'In their own words: New Labour women MPs and the substantive representation of women', British Journal of Politics and International Relations , 3.

CHILDS, S (2004a) 'A feminized style of politics? Women MPs in the House of Commons, British Journal of Politics and International Relations, 6 (1):3-19

CHILDS, Sarah (2004b) New Labour's Women MPs: Women Representing Women, London: Routledge

CHILDS S and Krook M L (2006a) 'Gender and politics: the state of the art' in Politics, 26 (1): 18-28

CHILDS S and Krook M L (2006b) 'Should feminism give up on critical mass? A contingent yes' in Politics and Gender 2 (4): 522-530

CHILDS S and Withey, J (2006) 'The substantive representation of women: the case of the reduction of VAT on sanitary products' in Parliamentary Affairs, 59(1): 10-23

CONNELL, R (2006) 'The experience of gender change in public sector organizations' in Gender, Work and Organization 13 (5): 435-452

DAHLERUP, D (2006) 'The story of the theory of critical mass' in Politics and Gender, 2 (4):511-522

EDWARDS, J and McAllister, L (2002) 'One step forward, two steps back? Women in the two main political parties in Wales' in Parliamentary Affairs, 55: 154-166

FRANZWAY, S, Court, D and Connell, R (1989) Staking a claim: feminism, bureaucracy and the state, Polity Press: Cambridge

FREEDMAN, J (2002) 'Women in the European Parliament' in Parliamentary Affairs, 55: 179-188

GREY, S (2006) 'Numbers and beyond: the relevance of critical mass in gender research in Politics and Gender 2 (4):492-502

GREY, S (2002) Does size matter? Critical mass and New Zealand's women MPs, Parliamentary Affairs, 55 (1): $19-29$

HALFORD, S and Leonard, P (2001) Gender, power and organisations, Palgrave: Basingstoke

KENNY, M (2007) 'Gender, institutions and power: a critical review', Politics, 27 (2): 91-100

LIDDLE J and Michielsens, E (2007) "'NQOC" Social identity and representation in British politics' in British Journal of Politics and International Relations, 9(4): 1369-1481

LIDDLE J and Michielsens, E (2000) 'Gender, class and political power in Britain' in S M Rai (ed) International perspectives on gender and democratisation, Macmillan: Basingstoke

LOVENDUSKI, J (2005) Feminizing politics, Cambridge: Polity

MACKAY, F (2008) "'Thick" conceptions of substantive representation: women, gender and political institutions' in Representation, 44 (2):125-138 
MACKAY, F (2004) 'Gender and political representation in the UK: the state of the discipline', British Journal of Politics and International Relations, 6 (1):99-120

MACKAY, F, Myers, F and Brown, A (2003) 'Towards a new politics? Women and the constitutional change in Scotland' in A. Dobrowolsky \& V. Hart (eds) Women Making Constitutions: New Politics and Comparative Perspectives, Basingstoke: Palgrave: 84-98

PUWAR, N (2004) 'Thinking about making a difference' in British Journal of Politics and International Relations, 6:65-80

REES, T. (1999) Women and Work: Twenty-five Years of Gender Equality in Wales, Cardiff: University of Wales Press.

ROSS, K (2002) 'Women's place in 'male' space: gender and effect in parliamentary contexts' in Parliamentary Affairs 55: 189-201

SONES B with Moran, M and Lovenduski, J (2005) Women in Parliament: the new suffragettes, Politico's: London

STOKES, W. (2005) Women in Contemporary Politics, Cambridge: Polity Press.

STUDLAR, D. T. \& McAllister, L. (2002) 'Does critical mass exist? A comparative analysis of women's legislative representation since 1950', European Journal of Political Research 41: 233-53.

SQUIRES, J (1999) Gender in political theory, Polity Press: Cambridge

TODAY IN PARLIAMENT (23/5/08) http://news.bbc.co.uk///hi/programmes/bbc_parliament/7422255.stm accessed $29 / 5 / 08$

TREMBLAY, M (2006) 'The substantive representation of women and PR: some reflections on the role of surrogate representation and critical mass' in Politics and Gender 2 (4): 502-511

TREMBLAY, M (2003) 'Women's representational role in Australia and Canada: the impact of political context', Australian Journal of Political Science , 38 (2): 215-38

WACJMAN, J (1998) Managing like a man, Polity Press: Cambridge

WATT, N (2003) 'Equality: women win half Welsh seats' in The Guardian Newspaper, 3rd May

WILLIAMSON, D. (2008) 'Longer working week at the Assembly after Labour members agree to deal' Western Mail 5 March

WITZA and Savage M, (1992) 'The gender of organizations' in M.Savage and A. Witz (eds) Gender and bureaucracy, Blackwell Publishers/ The Sociological Review: Oxford: 3-62 